\title{
Influence of Intergenerational and Peer-to-Peer Knowledge Sharing on Academics' Creativity
}

\author{
Dongxia Huo ${ }^{1} \&$ Sarana Photchanachan ${ }^{2}$ \\ ${ }^{1} \mathrm{Ph}$. D Candidate, Management, School of Management, Shinawatra University, Thailand \\ ${ }^{2}$ Management, School of Management, Shinawatra University, Thailand \\ Correspondence: Dongxia Huo, Management, School of Management, Shinawatra University, Thailand.
}

Received: April 19, 2021

Accepted: May 8, $2021 \quad$ Online Published: May 14, 2021

doi:10.5539/ibr.v14n6p91

URL: https://doi.org/10.5539/ibr.v14n6p91

\begin{abstract}
The objectives of this paper were to study the different relationships between different types of knowledge sharing and academics' creativity and found these results: 1) Intergenerational Knowledge Sharing (IGKS) positively related to academics' creativity. 2) peer-to-peer knowledge sharing (PPKS) positively related to academics' creativity. 3) online knowledge sharing has a stronger influence on creativity than offline knowledge sharing. 4) Regardless of the communication method used, the positive impact of intergenerational knowledge sharing on academics' creativity is stronger than peer-to-peer knowledge sharing.
\end{abstract}

Keywords: academics' creativity, intergenerational knowledge sharing, offline communication, online communication, peer-to-peer knowledge sharing

\section{Introduction}

With the advent of the knowledge economy, knowledge transfer, integration, sharing, creativity, and innovation have become important research issues in the fields of knowledge management and knowledge innovation in recent years (Pittaway, Robertson, Munir, et al., 2004). Creativity and innovation have become one of the important contents of China's current innovation and development. In contemporary society, creativity and innovation are reflected in various fields and have become the sources of competitive advantage for individuals, universities, regions and even countries (Elroy, 2000). Due to less research study of this topic in China even though the subject is becoming more and more important, the author of this current study aims to investigate the influence of knowledge sharing on academics' creativity. Lin (2007) argued that employees with high academic qualifications and rich work experience are more willing to share knowledge in the organization, so the author chooses academics as research objective.

At present, research in the field of knowledge sharing pays more attention to the impact of team innovation (Liu\& Phillips, 2011) and organizational innovation (Gloet \& Terziovski, 2004); Some research indicates that knowledge sharing can have a significant positive impact on individual innovation ability (Wan \& Chen, 2012); There are also a few cases that indicate intergenerational knowledge sharing positively related to creativity. Knowledge sharing can promote the younger generation to acquire new knowledge (Novackova, 2016), but no research has found any difference in the effect of intergenerational and peer-to-peer knowledge sharing. Also, although studies have pointed out that social media can achieve organizational innovation by promoting organizational knowledge sharing (Leonardi, 2014), However, the past researches show that there is no difference between online knowledge sharing and offline knowledge sharing impact on academic creativity.

Wan Qing examined the knowledge sharing among academics within an organization have a significant positive impact on individual creativity (Wan \& Chen, 2012). However, the aging of the population has led to multiple "generations" of internal cooperation, and the sources of knowledge that young academics can access are more diverse. They can establish contacts, communicate with each other, and exchange with elder generations of academics or generations of academics. Different types of knowledge and experience to accomplish common tasks and achieve common goals (Joshi \& Dencker, 2010). Besides, the development of information technology has made communication between academics within the organization more diversified. Young academics can choose online communication methods of information technology support or face-to-face offline communication methods, with elder generation academics or generations of academics' exchange knowledge (Zhang, Venkatesh, 
2014). Due to the different types of knowledge that elder colleagues have the benefits of acquiring knowledge (intergenerational knowledge sharing) with elder academics and acquiring knowledge (peer-to-peer knowledge sharing) with peers may vary. Offline and online communication is the transmission of context information, the resolution of time and space constraints, the parallel transmission of information, the information documentation and retrieval have different performances, and the effects of online communication and offline communication may also be different (Zhang, Venkatesh, 2014).

Therefore, it is necessary to clarify the differences in the impact of different generations of employees in different communication directions on the creativity of employees. To compensate for the shortcomings of existing research, this paper will analyze two different dimensions of knowledge sources (older/peer colleagues) and communication methods (use of information technology). Divide knowledge sharing into 4 types of online intergenerational knowledge sharing, online peer-to-peer knowledge sharing, offline intergenerational knowledge sharing, offline Peer knowledge sharing, and research academics to gain different influences on their creativity by participating in different types of knowledge sharing.

\section{Theory and Hypotheses}

Argote proposed a theoretical framework based on knowledge management results and context (Argote, Mcevily, 2003). The theory points out that the contextual factors affecting the effect of knowledge management include the unit attributes of participation in knowledge management, the relationship attributes between units, and the knowledge attributes. Under the guidance of this theory, this paper reviews existing knowledge sharing research and identifies four knowledge sharing characteristics factors that are conducive to individual creativity: knowledge unit attributes internal motivation of the sharing party (Lou \& Fang, 2003); unit relationship attributes (knowledge time complementarity and spatial complementarity); knowledge attributes abstract high-level knowledge (Hinds, Patterson, Pfeffer, 2001). Absorbing the knowledge of older workers can help younger workers achieve this Knowledge creation; The experience of older workers can help younger one Accurate evaluation and improvement of new programs and provision for their implementation Support; Older workers' networks can also help younger workers Realize innovation point to provide help. From this, the elders are often older Young workers who acquire knowledge there are more likely to generate and disseminate it and implement new ideas or programs. Generally speaking, young employees can choose to go offline or online Communicate with older employees to gain valuable knowledge. Based on this, this paper compares and analyzes the performance of different types of knowledge sharing on these attribute characteristics, and develops the following sets of assumptions:

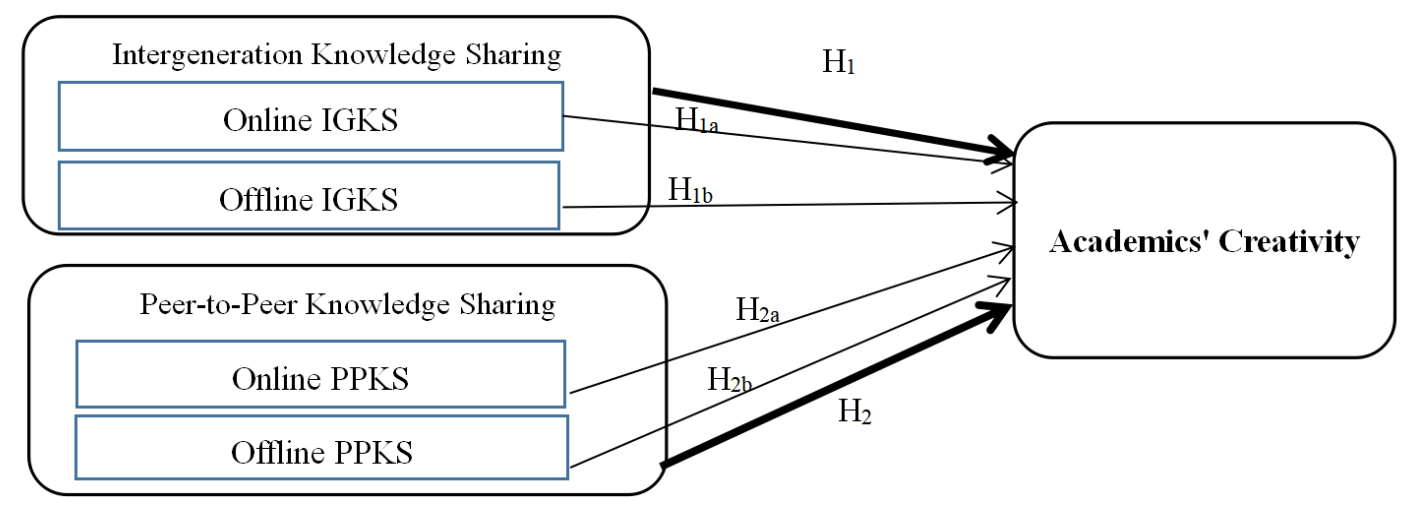

Figure 1. The conceptual model

H1: Intergenerational knowledge sharing (IGKS) has a significant impact on academics' creativity.

H1a: Online intergeneration knowledge sharing (Online IGKS) has a significant impact on academics' creativity.

H1b: Offline intergeneration knowledge sharing (Offline IGKS) has a significant impact on academics' creativity.

H2: Peer-to-peer knowledge sharing (PPKS) has a significant impact on academics' creativity.

H2a: Online peer-to-peer knowledge sharing (Online PPKS) has a significant impact on academics' creativity.

H2b: Offline peer-to-peer knowledge sharing (Offline PPKS) has a significant impact on academics' creativity. 


\section{Method}

\subsection{Data Collection}

This paper uses snowball sampling to collect data. The author first sent out the questionnaire to the academics that the author knew, such as academics from the Renmin University of China, academics from Beijing Institute of Technology, academics from Beijing Normal University, academics from Capital University of Economics and Business etc., and then requested them to forward the questionnaire to the academics they knew. Each university sent out 27-30 questionnaires. According to this method, a total of 420 questionnaires were sent out, 412 were recollected, 5 invalid questionnaires (with incomplete data) were excluded, finally 407 were effective, the effective rate was $96.67 \%$.

\subsection{Measurement Development}

Bock et al. were used to measure the five items of knowledge sharing, and the online (offline) intergenerational (Peer-to-Peer) knowledge sharing was measured and adjusted according to the research situation. For example, "through online (off-site face-to-face communication, such as telephone, WeChat, Line, forum, QQ, E-mail, SMS, audio or video conferencing and other online communication tools) / offline (face-to-face communication, such as daily communication, seminars, academics Conferences, academic salons, academic reports, lectures, etc.) Communication methods, from the elderly (10 years older than themselves) / Peers (with their age is less than 10 years old) colleagues get the frequency of work experience or work skills."

The creativity scale uses the nine items used in the literature (Janssen, 2000) to objectively measure the creativity of academics. All constructive measurement items were measured using the Likert 5-point scale (1-never; 2-sometimes; 3-usually; 4-often; 5-always).

\section{Analyses and Results}

\subsection{Descriptive Analysis}

Descriptive analysis is the use of tabulation and classification, graphics and computing summary data to describe the characteristics of data activities. The descriptive analysis of each problem in this paper was expressed by means and percentages.

Descriptive analysis is the use of tabulation and classification, graphics and computing summary data to describe the characteristics of data activities. The descriptive analysis of each problem in this paper was expressed by means and percentages.

In the sample, the respondents were 219 male (54\%) and 188 females. Male academics are slightly more than female academics. In the $41-50$ age group, there are 116 people (28.5\%), followed by the $36-40$ age group (21.4\%), and the third group of 31-35 years old (18.4\%) and the next over 50 years old(17\%), the last one, under 30 years old(14.7\%), which means that the majority of university academics are between 30 and 50 years old. 230 of the respondents, representing $56.5 \%$ of the sample, are $\mathrm{PhD}$ and above, followed by the Master's level of education (38.8\%), with only 19 people having a Bachelor's degree and below (4.7\%). The work experience of most of the people in the sample is mostly 11-20 years (31\%), followed by less than 5 years (23\%), 21-30 years (17\%), 6-10 years $(15 \%)$, more than 30 years $(14 \%)$. The academic age of the people in the sample is 11-20 years $(33.7 \%)$, followed by $6-10$ years $(26 \%)$, less than 5 years $(23.1 \%), 21-30$ years $(11.3 \%)$, more than 30 years $(5.9 \%)$.There are 134 respondents have professional titles associate professor (32.9\%), followed by the professor (26.3\%), lecture (25.8\%), teaching assistant and below (15\%).

\subsection{Reliability and Validity Analysis}

\subsubsection{Reliability Analysis}

Wu Minglong (2010) argued that the CITC value was greater than 0.4, the deleted Cronbach alpha value was greater than 0.7, and the total Cronbach alpha value was greater than 0.7 , indicating that the reliability of the scale met the analysis requirements. The test for general content validity depends on whether or not the scale is used. This paper uses mature scales to ensure content validity to a certain extent. As for structure validity, KMO value is considered to be greater than 0.7 , so factor analysis can be conducted. Bartlett's Test of Sphericity is statistically significant, and the factor loading of each item is above 0.5 .

As shown in Table 1 below, for the reliability analysis of the IGKS, PPKS, Academics' Creativity, the CITC value are $0.721,0.688,0.621$ greater than 0.4. The Total Cronbach's Alpha are 0.949, 0.96,0.88 which are greater than 0.7 , indicate that the overall reliability level is high and there is no need to delete the item. Therefore, the items of the IGKS, PPKS, and Academics' Creativity scale have good reliability and meet the requirements of data analysis. 
Table 1. Reliability Test Results of Intergenerational Knowledge Sharing

\begin{tabular}{lll}
\hline Item Code & CITC & Cronbach's Alpha \\
\hline IGKS & 0.721 & 0.949 \\
PPKS & 0.788 & 0.96 \\
Academics' Creativity & 0.621 & 0.88 \\
\hline
\end{tabular}

\subsubsection{Validity Analysis}

The validity analysis main analyzes the Content Validity, Construct Validity, Convergent validity and Discriminate validity of the scale. Regarding the content validity, because the scale of the variables in this paper is based on the maturity scale, it has good content validity. Regarding the Construct validity, this paper main test the KMO value. If the KMO value is greater than 0.7 , it is considered that the factor is suitable for factor analysis. The main factor analysis considers the component factor, and the component factor is greater than 0.4. Fulfilling the two points above provides good construct validity.

The KMO values of IGKS and PPKS are 0.92, 0.929 higher than 0.7 and the Bartlett's Test of Sphericity is significant, the component factors are all higher than 0.5 , and the analysis results are good. The KMO of academics' Creativity value is 0.897 higher than 0.7 and the Bartlett's Test of Sphericity is significant, the component factors are all higher than 0.5 , and the analysis results are good.

To verify Convergent validity and Discriminate validity, the factor load is tested (Appendix A). It can be seen from Table 2 that the load of each construct item is above 0.65, which exceeds the standard value of 0.5 , indicating that the Convergent validity of the convergence is better, each item has a greater load on its corresponding construct. The load on other constructs proves that there is a certain discriminant validity between Variables.

\subsection{Correlation Analysis}

In this paper, SPSS 24.0 software is used for correlation analysis of the sample data, and the analysis results of the correlation between the variables are shown in Appendix B.

\subsection{Tests of Hypotheses}

\subsubsection{Regression Analysis of Intergenerational Knowledge Sharing on Academics' Creativity}

The results of the multiple linear regression showed that the overall model was significant $(\mathrm{F}=106.50, \mathrm{p}<0.001$, $\left.\mathrm{R}^{2}=0.84\right)$. Table 2 , Model 1 analyzes the impact of control variables on academics' creativity. There are potential impacts such as age, gender, education background, working years, professional title, academic age and university level on academics' creativity. The regression results show that the $\mathrm{F}$ value is 2.87 , and these seven control variables have a low education background of interpretation of academics' creativity $\left(R^{2}=0.05\right)$.

Table 2. Regression Analysis Results by IGKS

\begin{tabular}{lcccc}
\hline \multirow{2}{*}{ Variables } & \multicolumn{3}{c}{ IGKS } \\
\cline { 2 - 4 } & Model-1 & Model-2 & Model-3 & Model-4 \\
\hline Age & $0.12^{* *}$ & $0.10^{* *}$ & $0.09^{* *}$ & $0.08^{* * *}$ \\
Gender & 0.07 & 0.06 & 0.06 & 0.05 \\
Education Background & $0.25^{* *}$ & $0.23^{* *}$ & $0.22^{* *}$ & $0.20^{* *}$ \\
Working Years & $0.2^{*}$ & $0.18^{*}$ & $0.17^{*}$ & $0.17^{*}$ \\
Academic Age & $0.22^{*}$ & $0.22^{*}$ & $0.21^{*}$ & $0.20^{*}$ \\
Professional Title & $0.49^{* *}$ & $0.46^{* *}$ & $0.44^{* *}$ & $0.45^{* *}$ \\
University Lever & $0.25^{*}$ & $0.26^{*}$ & $0.24^{*}$ & $0.21^{*}$ \\
Online IGKS & & $0.34^{* * *}$ & $0.31^{* * *}$ & \\
Offline IGKS & & & $0.25^{* *}$ & $0.53^{* * *}$ \\
IGKS & & & 0.52 & 0.37 \\
$\mathrm{R}^{2}$ & 0.31 & 0.4 & 0.12 & 0.06 \\
$\triangle \mathrm{R}$ & & 0.23 & $3.15^{* * *}$ & $3.54^{* * *}$ \\
$\mathrm{~F}$ & $2.87^{* *}$ & $4.44^{* * *}$ & & \\
\hline
\end{tabular}

$* \mathrm{p}<.05 ; * * \mathrm{p}<.01 ; * * * \mathrm{p}<.001 ;$ two-tailed; 
From Table 2 Model 2 analyzes the online intergenerational knowledge sharing impact on academics' creativity, the results of the regression showed that $F$ value is 4.44 , Regression equation is significant, $R^{2}$ is 0.4 . The $R^{2}$ indicated that the set of independent variables explained $40 \%$ of the dependent variability in academics' creativity. Specifically, the regression coefficient of online IGKS is 0.34 and shows significant $(\beta=0.34, p<$ 0.001) supports Hypothesis 1a.

Model 3 analyzes the offline intergenerational knowledge sharing impact on academics' creativity, the results of the regression showed that $F$ value is 3.14 , Regression equation is significant, $R^{2}$ is 0.52 . The $R^{2}$ indicated that the set of independent variables explained $52 \%$ of the dependent variability in academics' creativity. The effect of offline IGKS on academics' creativity was significantly positive $(\beta=0.25, p<0.01)$. Thus, Hypothesis $1 b$, which states that the offline intergenerational knowledge sharing impact on academics' creativity, was supported.

Model 4 analyzes the intergenerational knowledge sharing (IGKS) impact on academics' creativity, the change of F value show significance $(\mathrm{p}<0.001)$, which means that IGKS has an explanatory meaning for the model. Also, the increase of $\mathrm{R}$ squared value from 0.05 to 0.17 means that IGKS can produce $17 \%$ explanatory power for academics' creativity. Specifically, the regression coefficient of IGKS is 0.53 and shows significant $(\beta=0.53, p<$ 0.001). Thus, Hypothesis 1 was supported.

\subsubsection{Regression Analysis of Peer-To-Peer Knowledge Sharing on Academics' Creativity}

From Table 3, Model 5 analyzes the online peer-to-peer knowledge sharing impact on academics' creativity, the results of the regression showed that $F$ value is 4.54 , Regression equation is significant, $R^{2}$ is 0.59 . The $R^{2}$ indicated that the set of independent variables explained 59\% of the dependent variability in academics' creativity. Specifically, the regression coefficient of online PPKS is 0.28 and shows significant $(\beta=0.28, p<0.01)$ supports Hypothesis $2 \mathrm{a}$.

Model 6 analyzes the offline peer-to-peer knowledge sharing impact on academics' creativity, the results of the regression showed that $F$ value is 6.12, Regression equation is significant, $R^{2}$ is 0.61 . The $R^{2}$ indicated that the set of independent variables explained $61 \%$ of the dependent variability in academics' creativity. The effect of offline PPKS on academics' creativity was significantly positive $(\beta=0.16, p<0.05)$. Thus, Hypothesis $2 b$, which states that the offline peer-to-peer knowledge sharing impact on academics' creativity, was supported.

Table 3. Regression Analysis Results by PPKS

\begin{tabular}{lccc}
\hline \multirow{2}{*}{ Variables } & \multicolumn{2}{c}{ PPKS } & Model-6 \\
\cline { 2 - 4 } Model-5 & $0.23^{* *}$ & \\
\hline Control Variable & $0.28^{* * *}$ & $0.16^{*}$ & \\
Online PPKS & & & $0.41^{* * *}$ \\
Offline PPKS & & 0.61 & 0.54 \\
PPKS & 0.59 & 0.03 & 0.02 \\
$\mathrm{R}^{2}$ & 0.05 & $6.12^{* *}$ & $3.59^{* *}$ \\
$\triangle \mathrm{R}^{2}$ & $4.54^{* *}$ & \\
$\mathrm{~F}$
\end{tabular}

$* \mathrm{p}<.05 ; * * \mathrm{p}<.01 ; * * \mathrm{p}<.001 ;$ two-tailed;

Model 7 analyzes the peer-to-peer knowledge sharing (PPKS) impact on academics' creativity, the change of F value shows significance $(\mathrm{p}<0.01)$, which means that PPKS has an explanatory meaning for the model. Also, the R squared value is 0.54 , what means that PPKS can produce $54 \%$ explanatory power for academics' creativity. Specifically, the regression coefficient of PPKS is 0.41 and shows significant $(\beta=0.41, p<0.001)$. Thus, Hypothesis 2 was supported.

Through the above empirical analysis, the verification results of all relevant research hypotheses in this thesis are obtained.

\section{Conclusion}

\subsection{Major Findings}

This paper found that intergenerational knowledge sharing was positively related to academics' creativity. This shows that intergenerational knowledge sharing can promote academics to create more new ideas, and provide data support for the ideas of intergenerational knowledge sharing that is beneficial to knowledge creation. Different from the existing research, this paper distinguishes between online and offline intergenerational knowledge sharing. Results show that online intergenerational knowledge sharing is positively related to 
academics' creativity. Offline intergenerational knowledge sharing positively related to academics' creativity. And this paper finds that the positive impact of online intergenerational knowledge sharing on academics' creativity is stronger than offline intergenerational knowledge sharing.

Peer-to-peer knowledge sharing is positively related to academics' creativity. Online peer-to-peer knowledge sharing is positively related to academics' creativity. This shows that often obtaining knowledge from peers of the same age through non-face-to-face communication favors the generation, promotion, and application of innovative ideas. Different from the existing research, this paper distinguishes the knowledge sharing between online and offline peers, and finds that online and offline peer-to-peer knowledge sharing is positively related to academics' creativity.

This paper finds that online knowledge sharing has a stronger influence on creativity than offline knowledge sharing. This is because today's social Internet technology is highly developed, and the use of smart phones and computers is very extensive. University academics are more willing to adopt online way to sharing knowledge. In face-to-face communication, the possibility of sharing feelings rather than sharing knowledge is higher.

Regardless of the communication method used, the positive impact of intergenerational knowledge sharing on academics' creativity is stronger than peer-to-peer knowledge sharing. Studies have shown that compared to beginners, experts provide task guidance for novices, which is more conducive to designing new solutions in different situations. This paper provides data support for this conclusion. Elder academics as experts will provide more high-level knowledge when providing guidance to young academics. These high-lever knowledge academics can help young academics master the rules of solving problems in different situations, and it is more conducive to them to generate, promote and implement new ideas.

\subsection{Theoretical Contributions}

This paper explores the influence of knowledge sharing on creativity from the perspective of intergenerational and peers, and has certain theoretical enlightenment on the future research of knowledge sharing theory. At present, research in the field of knowledge sharing pays more attention to the impact of team innovation (Liu \& Phillips, 2011) and organizational innovation (Gloet \& Terziovski, 2004); Some research indicates that knowledge sharing can have a significant positive impact on individual innovation ability (Wan \& Chen, 2012); There are also a few cases that indicate intergenerational knowledge sharing positively related to creativity. Knowledge sharing can promote the younger generation to acquire new knowledge (Novackova, 2016), but no research has found any different relationship between intergenerational and peer-to-peer knowledge sharing. This research has been studied from this perspective. This paper measures intergenerational knowledge sharing and peer-to-peer knowledge sharing from the perspective of knowledge sharing (online and offline). Also, although studies have pointed out that social media can achieve organizational innovation by promoting organizational knowledge sharing (Leonardi, 2014), the past researches show that there is no difference between online knowledge sharing and offline knowledge sharing impact on academics' creativity. This article provides data support for this purpose.

This paper studies the creativity of academics, and the results show that knowledge sharing can enhance academics' creativity. This is of great significance for academics to better share knowledge and enhance their abilities. Provide some theoretical guidance for future research to further explore the creativity of academics.

\subsection{Practical Contributions}

Academics' knowledge sharing can enhance their creativity. As national high-level scientific and technological talents, scientific research personnel are the key force in the construction of the national innovation system. Their creativity is very important to the development of individuals and the country. Therefore, university managers need to make employees aware of the benefits of knowledge sharing for creativity, stimulate the enthusiasm of employees in knowledge sharing, and enhance the ability of academics to build a good knowledge system.

Intergenerational knowledge sharing has a positive impact on academics' creativity. Colleges and universities should attach importance to the role of the traditional tutorial mechanism and encourage elder academics to share knowledge with others in a more open manner. Peer-to-peer knowledge sharing has a positive impact on academics' creativity. While university administrators attach importance to the traditional tutorial mechanism, they should also promote peer-to-peer learning. Online peer-to-peer knowledge sharing has a positive impact on academics' creativity. The enlightenment to managers is that the creativity of new generation academics is easier to generate in the network environment, so organizations need to pay attention to the guidance and cultivation of employees' creativity in the new network environment.

Therefore, the research results of this paper can provide certain guiding significance to practice, and academics 
should take an active part in knowledge sharing, which is of great help to improve their own and organizational creativity.

\section{Limitations}

There are several areas of research based on the data gathered from this paper that need further investigation. This paper only studies the influence of Intergenerational and peer-to-peer knowledge sharing on academics' creativity of universities in Beijing. The survey sample is only from the group of academics who work in universities in Beijing. In the future, it will consider collecting more sample data and expanding the scope to all of China. It can also include other industry data and use the industry as a control variable. Analyze the influence of knowledge sharing on employees' creativity.

Another area of research should focus on expanding this research. This paper only analyzes the different types of knowledge sharing (intergenerational and peer-to-peer) different ways of sharing communication (online, offline) and academics' creativity. In the future, it is also necessary to analyze the relationship between different types of knowledge sharing and job performance, competition.

\section{References}

Argote, L., Mcevily, B., \& Reagans, R. (2003). Managing Knowledge in Organizations: An Integrative Framework and Review of Emerging Themes. Management Science, 49(4), 571-582. https://doi.org/10.1287/mnsc.49.4.571.14424

Bock, G., Zmud, R. W., \& Kim, Y. et al. (2005). Behavioral Intention Formation in Knowledge Sharing: Examining the Roles of Extrinsic Motivators, Social-Psychological Forces, and Organizational Climate. MIS Quarterly, 29(1), 87-111. https://doi.org/10.2307/25148669

Bock, G., \& Kim, Y. G. (2002). Breaking the myths of rewards: an exploratory study of attitudes about knowledge sharing. Information Resources Management Journal, 15(4), 14-21. https://doi.org/10.4018/irmj.2002040102

Gloet, M., \& Terziovski, M. (2014). Exploring the Relationship between Knowledge Management Practices and Innovation Performance. Journal of Manufacturing Technology Management, 15(5), 402-409. https://doi.org/10.1108/17410380410540390

Hinds, P. J., Patterson, M., \& Pfeffer, J. (2001). Both-erred by Abstraction: The Effect of Expertise on Knowledge Transfer and Subsequent Novice Performance. Journal of Applied Psychology, 86(6), 1232-1243. https://doi.org/10.1037/0021-9010.86.6.1232

Janssen, O. (2000). Job Demands, Perceptions of Effort-Reward Fairness and Innovative Work Behavior. Journal of Occupational and Organizational Psychology, 73(3), 287-302. https://doi.org/10.1348/096317900167038

Joshi, A., Dencker, J. C., \& Franz, G. et al. (2010). Unpacking Generational Identities in Organizations. Academy of Management Review, 35(3), 392-414. https://doi.org/10.5465/amr.35.3.zok392

Leonardi, P. M. (2014). Social Media, Knowledge Sharing, and Innovation: Toward a Theory of Communication Visibility. Information Systems Research, 25(4), 796-816. https://doi.org/10.1287/isre.2014.0536

Lin, H. F. (2007). Effects of extrinsic and intrinsic motivation on employee knowledge sharing intentions. Journal of Information Science, 33(2), 135-149. https://doi.org/10.1177/0165551506068174

Liu, Y., \& Phillips, J. S. (2011). Examining the Antecedents of Knowledge Sharing in Facilitating Team creativity from a Multilevel Perspective. International Journal of Information Management, 31(1), 44-52. https://doi.org/10.1016/j.ijinfomgt.2010.05.002

Lou, J., Fang, Y., \& Lim, K. H. et al. (2013). Contributing High Quantity and Quality Knowledge to Online Q\&A Communities. Journal of the American Society for Information Science and Technology, 64(2), 356-371. https://doi.org/10.1002/asi.22750

Novackova, E. (2016). Effects of Intergenerational Learning in a Small Manufacturing Company. Studia Paedagogica, 21(2), 117-130. https://doi.org/10.5817/SP2016-2-8

Pittaway, L., Robertson, M., \& Munir, K. et al. (2004). Networking and innovation: A systematic review of the evidence. International Journal of Management Reviews, 6(3), 137-168. https://doi.org/10.1111/j.1460-8545.2004.00101

Wan, Q., \& Chen, W. M. (2012). The Relationship between knowledge sharing Path Selection Strategy and 
Employee Innovation Performance. Chinese Journal of Management, 9(12), 1786-1791.

Wu, M. L. (2010). Statistical Analysis of Questionnaires: SPSS Operation and Application. Chongqing: Chongqing University Press.

Zhang, X., \& Venkatesh, V. (2014). Explaining Employee Job Performance: The Role of Online and Offline Workplace Communication Networks. MIS Quarterly, 37(3), 695-722.

https://doi.org/10.25300/MISQ/2013/37.3.02

\section{Appendix A. Factor Load Test Result}

\begin{tabular}{|c|c|c|c|c|c|c|}
\hline Variables & Item Code & Academics' Creativity & Online IGKS & Offline IGKS & Offline PPKS & Online PPKS \\
\hline \multirow{9}{*}{$\begin{array}{l}\text { Academics' } \\
\text { Creativity }\end{array}$} & C_Q1 & 0.918 & & & & \\
\hline & C_Q2 & 0.864 & & & & \\
\hline & C_Q3 & 0.912 & & & & \\
\hline & C_Q4 & 0.846 & & & & \\
\hline & C_Q5 & 0.885 & & & & \\
\hline & C_Q6 & 0.831 & & & & \\
\hline & C_Q7 & 0.822 & & & & \\
\hline & C_Q8 & 0.869 & & & & \\
\hline & C_Q9 & 0.819 & & & & \\
\hline \multirow{5}{*}{ Online IGKS } & K_OG1 & & 0.815 & & & \\
\hline & K_OG2 & & 0.812 & & & \\
\hline & K_OG3 & & 0.882 & & & \\
\hline & K_OG4 & & 0.841 & & & \\
\hline & K_OG5 & & 0.902 & & & \\
\hline \multirow{5}{*}{ Offline IGKS } & K_FG1 & & & 0.742 & & \\
\hline & K_FG2 & & & 0.822 & & \\
\hline & K_FG3 & & & 0.894 & & \\
\hline & K_FG4 & & & 0.865 & & \\
\hline & K_FG5 & & & 0.864 & & \\
\hline \multirow{5}{*}{ Offline PPKS } & K_FP1 & & & & 0.781 & \\
\hline & K_FP2 & & & & 0.752 & \\
\hline & K_FP3 & & & & 0.841 & \\
\hline & K_FP4 & & & & 0.812 & \\
\hline & K_FP5 & & & & 0.895 & \\
\hline \multirow{5}{*}{ Online PPKS } & K_OP1 & & & & & 0.825 \\
\hline & K_OP2 & & & & & 0.816 \\
\hline & K_OP3 & & & & & 0.881 \\
\hline & K_OP4 & & & & & 0.852 \\
\hline & K_OP5 & & & & & 0.911 \\
\hline
\end{tabular}

\section{Appendix B. Correlation Matrix}

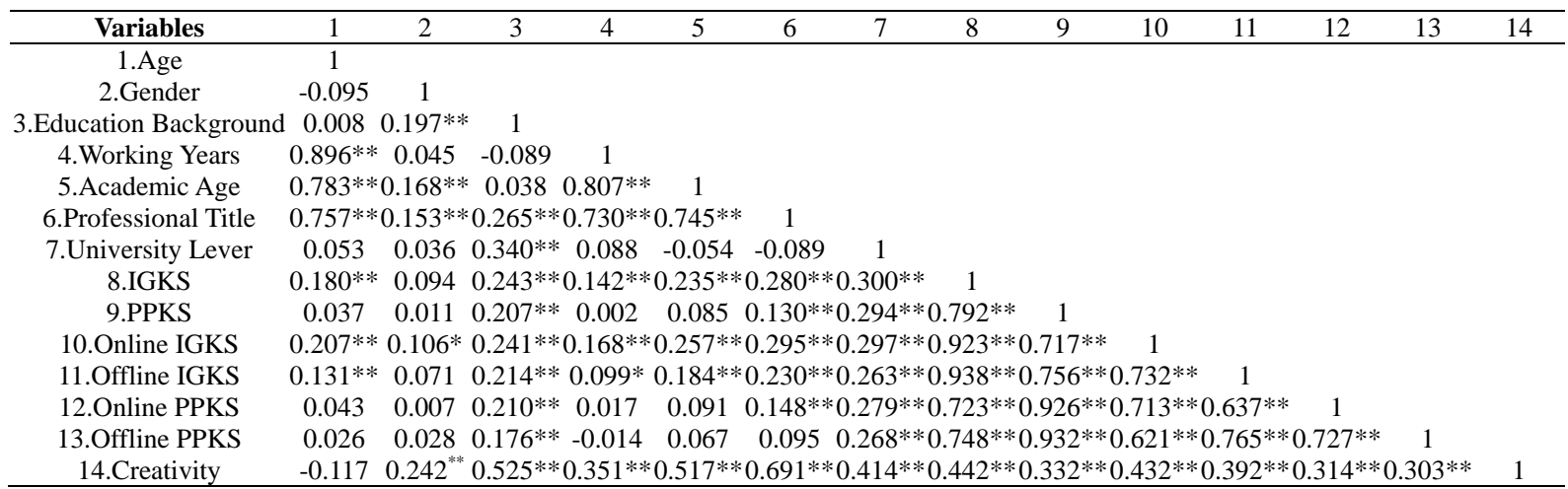

** Correlation is significant at the 0.01 level (2-tailed).

* Correlation is significant at the 0.05 level (2-tailed).

\section{Copyrights}

Copyright for this article is retained by the author(s), with first publication rights granted to the journal.

This is an open-access article distributed under the terms and conditions of the Creative Commons Attribution license (http://creativecommons.org/licenses/by/4.0/). 